\title{
WAGERING AGAINST DIVINE HIDDENNESS
}

\author{
ELIZABETH JACKSON
}

University of Notre Dame

\begin{abstract}
J.L. Schellenberg argues that divine hiddenness provides an argument for the conclusion that God does not exist, for if God existed he would not allow non-resistant non-belief to occur, but non-resistant non-belief does occur, so God does not exist. In this paper, I argue that the stakes involved in theistic considerations put pressure on Schellenberg's premise that non-resistant nonbelief occurs. First, I specify conditions for someone's being a non-resistant non-believer. Then, I argue that many people fulfil these conditions because, given some plausible assumptions, there is a very good pragmatic reason to be a theist rather than an atheist. I assume it is more likely that theists go to heaven than atheists, and I argue there is a non-zero probability that one can receive infinite utility and a method of comparing outcomes with infinite utilities in which the probability of each outcome affects the final expected values. Then, I show how this argument entails there is no good reason to think that there are very many non-resistant non-believers.
\end{abstract}

\section{INTRODUCTION}

The problem of divine hiddenness is defended today by J.L. Schellenberg. He argues that divine hiddenness supplies an argument for the conclusion that God does not exist, as follows:

S1. If God exists, he is perfectly loving.

S2. If a perfectly loving God exists, then non-resistant non-belief does not occur.

S3. Non-resistant non-belief occurs.

S4. No perfectly loving God exists [from S2, S3].

S5. Therefore, God does not exist [from S1, S4]. ${ }^{1}$

\footnotetext{
${ }^{1}$ Schellenberg (1993), (2005a), (2005b).
} 
The idea is that, if God exists, the fact that he is perfectly loving would cause him to have a 'bias for relationship' with his creatures. He would do everything he could to be in relationship with them. However, it seems like in order for a person to have a relationship with God, that person must believe God exists. But God's existence is not obvious; many people fail to believe simply because there isn't sufficient evidence or because of other factors for which they are not blameworthy. Schellenberg calls these people 'non-resistant non-believers'. They would love to know God and have a relationship with him if he existed, but they simply do not think there is enough evidence to reasonably believe God exists. The most salient characteristic of non-resistant non-believers is that they are not culpable for their nonbelief. ${ }^{2}$ Because non-resistant non-belief occurs, this gives us reason to think that a perfectly loving God does not exist. ${ }^{3}$

Traditionally, Schellenberg's argument has been challenged in two main ways. Many have denied premise (S2), saying that God might be perfectly loving but allows hiddenness for some greater good. Another response is to deny (S3) and claim that we do have evidence that God exists, so rationality prescribes belief in God - some people have just blinded themselves to the evidence. In this paper, I will not argue that premise (S2) is false or that premise (S3) is false; rather, I will argue something weaker: that there is no good reason to think that there are very many non-resistant non-believers. This conclusion entails that there are fewer non-resistant non-believers than many people will prima facie think, and also that there are fewer non-resistant non-believers than Schellenberg assumes. However, this might seem insignificant. After all, as long as an argument is valid, the only way to attack it is by denying one of its premises. However, there are three reasons why my thesis significantly counts against Schellenberg's argument.

\footnotetext{
${ }^{2}$ Schellenberg does, in some places, refer to them as 'non-culpable non-believers', but he seems to use 'non-resistant non-believers' more frequently, so I will adopt his terminology. However, non-culpable non-belief might actually be a better word choice. Rea (in conversation) has pointed out that one can be resistant to a belief without being culpable. (This parallels the point made by Wainwright [2001] that reasonable nonbelief and non-culpable nonbelief come apart). For example, I may be inculpably resistant to a racist belief because I think it would be immoral for me to hold it. (Schellenberg might respond to Rea and Wainwright that there are certain propositions, such as 'God exists' for which resistance always implies blame). The main point here is that the culpability, rather than the resistance, is the important factor for Schellenberg; this will be captured in the condition I give for non-resistant non-belief on page 3.

${ }^{3}$ Schellenberg (1993), (2005a), (2005b).
} 
The first has to do with the way Schellenberg's argument is set up; I think formulating the hiddenness argument deductively may be problematic. Of course, deductive arguments are nice and clean and easy to respond to (i.e. as long as the argument is valid, argue against one of its premises). The worry about framing Schellenberg's hiddenness argument deductively is that, as a deductive argument, it cannot capture the intuition that the number non-resistant non-believers matters. Consider three worlds:

World 1: There are no non-resistant non-believers.

World 2: There is one non-resistant non-believer; nonresistant nonbelievers are an extremely small percentage of people in the world.

World 3: There are 8 billion (or some arbitrarily high number) nonresistant non-believers; everyone or almost everyone in this world is a non-resistant non-believer.

Notice that the third premise is a claim about existence; it essentially states $\exists \mathrm{x}$ ( $\mathrm{x}=\mathrm{a}$ non-resistant non-believer). For this reason, the argument does not distinguish between the non-resistant non-belief in World 2 and in World 3. Do we really want to say that we are in the exact same evidential situation with respect to theism in both worlds? This seems implausible, and I think this is good evidence that the simple deductive hiddenness argument is too coarse grained.

Someone might resist the above by insisting that the existence of just one non-resistant non-believer significantly lowers the probability of theism. Once we know one exists, theists have a big problem on their hands, so the number of non-resistant non-believers, as long as it is non-zero, isn't that weighty. In response, I want to note that everything I've said is consistent with the probability of theism in World 1 being much higher than in World 2. The probability of theism might even take a huge drop from World 1 to World 2, and a much smaller drop from World 2 to World 3. For example, one might think the probability of theism in World 1 is 0.6 , while it's 0.2 in World 2 and 0.1 in World 3. This is consistent with what I'm arguing. My main concern is that Schellenberg's original formulation of the hiddenness argument will not allow us to capture any differences in the probability of theism between Worlds 2 and 3. 
Suppose that the number of non-resistant non-believers matters for the probability of theism (and not just in the zero to one case). If this is right, something like the following seems true:

Inductive Hiddenness Proposition (IHP): The probability of theism is inversely correlated with the amount of non-resistant non-belief that occurs. ${ }^{4}$

Given IHP, it becomes clear why my thesis, that there are not very many non-resistant non-believers, is significant. The less non-resistant nonbelief there is, the less non-resistant belief counts against theism, and the less Schellenberg's argument lowers the probability of theism.

Even if someone completely rejects this first reason my thesis counts against Schellenberg, there are two other reasons my thesis is significant that do not depend on taking the hiddenness argument inductively. The first is the role my thesis plays in a larger argument that (S2) is false. Suppose God allows hiddenness for some greater good. For example, suppose it is very valuable that humans have free will, but that some humans make free decisions that cause God to be hidden for other humans (who are non-resistant non-believers). Consider again World 2 and World 3. It is plausible that, given theism, World 3 is a worse state of affairs than World 2. So, the good of free will might outweigh the bad of a small amount of non-resistant non-belief, such as in World 2, but not a huge amount of non-resistant non-belief, such as in World 3. This example generalizes: if there are fewer non-resistant non-believers, at least some greater goods defences will become more plausible. Thus, an argument that there are fewer non-resistant non-believers than one might prima facie think can be combined with a greater goods defence to make an outright denial of (S2) more plausible.

One might worry that this sort of response depends on there being a substantial difference between Worlds 2 and 3. However, this difference is not an evidential difference - a difference in the probability of theism - but an axiological difference - a difference in the value of

\footnotetext{
${ }^{4}$ Note that the rate at which the probability of theism drops may not be the exact same as the rate at which non-resistant non-belief increases. As I noted earlier, the probability of theism may take a huge drop when the number of non-resistant non-believers goes from 0 to 1 . The point is just that as one number increases (the number of non-resistant non-believers) the other decreases (the probability of theism). I am not making any claims about the rate at which this happens.
} 
the worlds, given theism. So, this response depends on World 3 being a worse state of affairs (given theism) than World 2. This is a notably different assumption than the one that played a large role in my first line of reasoning. It also seems pretty plausible to me, but if one is also not convinced, there is a third way my argument is significant that doesn't depend on either kind of difference between Worlds 2 and 3.

This third way involves an argument against Schellenberg that ultimately denies premise (S3). One natural way to argue that there are no non-resistant non-believers is to give arguments that make the number smaller and smaller, until one has established that there are none. My argument can be combined with other arguments against the occurrence of non-resistant non-belief to ultimately establish that there are no non-resistant non-believers. This is a relatively simple response, but of course, has the cost of denying that non-resistant non-belief occurs, a proposition that strikes many as implausible.

So, there are at least three ways my thesis can significantly weaken Schellenberg's argument. But why think there are not very many nonresistant non-believers? In this paper, I argue that non-resistant nonbelief is uncommon, but I argue this from a novel angle. Most people who have responded to Schellenberg have taken the word 'non-resistant non-belief' to have a narrow scope - referring to only epistemic norms. In other words, non-resistant non-believers are blameless because they have fulfilled their epistemic duties with respect to the proposition 'God exists'; resistant non-believers are culpable because of their epistemic failures. For example, resistant non-believers' beliefs may not be based on evidence, they may have failed to fulfil their evidence gathering duties, or they may be engaged in self-deception. Their blamelessness or blameworthiness can be traced back to their doxastic attitudes or another distinctly epistemic factor.

However, I want to examine Schellenberg's arguments taking 'nonresistant non-belief' to have a larger scope, one that also takes prudential norms into consideration. I take prudential norms to be a function of probability and utility, while epistemic ones are merely about probability. Resistant non-believers are blameworthy because of a means-end failure; their culpability is not necessarily traced back to something distinctly epistemic (although it could be, because prudential rationality has an epistemic component). So, rather than arguing that there is sufficient epistemic reason for people to believe in God, I argue that there is 
sufficient prudential reason to form belief in God. ${ }^{5}$ Because many people have such a strong pragmatic reason to believe in God, God is not hidden for those people, so they are not non-resistant non-believers.

My argument does not depend on producing sound arguments that God exists; rather, it depends on a story about why it is prudentially rational to believe in God. I intend to show that the prudential rationality of theism comes down to a particular probability judgment that most people will accept. Specifically, when prudential norms are considered, Schellenberg's argument is no longer about the probability of theism vs. the probability of atheism. Rather, it is about the probability atheists will receive benefits in the afterlife vs. the probability that theists will receive benefits in the afterlife. ${ }^{6}$ This drastically changes the hiddenness debate.

The paper is structured as follows. In section II, I outline and explain my basic argument. In section III, I defend the second premise of my argument, arguing that if one wants to increase one chances of receiving infinite utility in the afterlife, one should be a theist. In section $I V$, I respond to objections, and in section $V$, I explain specifically how my argument counts against Schellenberg.

\section{THE BASIC ARGUMENT}

The fundamental claim I want to defend in this paper is the following: given the success of (a version of) Pascal's Wager, there is no good reason to think that there are very many non-resistant non-believers. In other words, resistant non-belief is a fairly common phenomenon. Important for my argument is the concept of resistant non-belief. This is also salient for Schellenberg, but to my knowledge, he never provides formal conditions for being a resistant non-believer. To both illuminate what counts as resistant and to be as clear as possible, I offer the following sufficient condition for a resistant doxastic attitude:

${ }^{5}$ Here, I do not mean for 'epistemic' and 'prudential' failures to exclude moral failures. In this paper, I will assume there can be instances of epistemic and prudential failures that are also moral failures. In fact, most of the epistemic/prudential failures I am interested in are also probably moral ones; I am suspicious that there is such a thing as non-moral culpability. For more on this, see Dougherty (2012).

${ }^{6}$ Even if one questions the probability assumption, this paper still shows how the Schellenberg problem, when prudential reasons are taken into consideration, turns into a surprising and interesting debate about the nature of the afterlife. 
$S$ is resistant with respect to a proposition $\mathrm{p}$ if

(1) (i) $S$ believes $<$ she has a stronger reason to believe $p$ than to hold any other doxastic attitude toward $p>O R$ (ii) $S$ is blameworthy for lacking the belief in (i),

(2) S has control over her doxastic attitude toward p, and

(3) $S$ chooses not to believe $p$.

Note that this is merely a sufficient condition for a resistant doxastic attitude - there may be other ways for someone to be resistant as result of a doxastic attitude they have. However, all I need is a sufficient condition because I just want to argue that many people fulfil the above condition. Nonetheless, resistant belief may occur in other ways. ${ }^{7}$

I will argue that many non-believers fulfil (1) because they have a stronger reason to believe God exists than to hold any other doxastic attitude toward the proposition, and they are either aware of this or are culpable for not being aware of it. My basic argument is as follows:

(1) One should perform the action that maximizes EV.

(2) Cultivating belief in God maximizes EV.

(3) Therefore, one should cultivate belief in God [1,2].

Premise 1: I will simply assume this premise for the sake of this paper. I know challenges have been brought to this premise in several paradoxes such as the St. Petersburg paradox,${ }^{8}$ the Pasadena paradox, ${ }^{9}$ etc. However, the 'maximize EV' norm is a classic and orthodox norm for prudential rationality and has quite a bit of intuitive appeal. For this reason, I do not take this to be a highly controversial assumption. Either way, it is an assumption of my argument; defending this premise lies beyond the scope of this paper. ${ }^{10}$

Premise 2: This premise states that S's cultivating belief in God maximizes expected value. This is because S's being a theist increases the probability $\mathrm{S}$ will receive infinite utility (presumably, in the afterlife). I will spend the rest of the paper defending this premise, because I take it to be the

7 Thanks to Blake McAllister.

${ }^{8}$ See Martin (2013).

${ }^{9}$ See Nover and Hajek (2004).

${ }^{10}$ Later in this paper, I will suggest that the maximize-EV norm should be modified in the infinite case. However, my main suggestion is not a denial that one should maximize expected value, but that one should calculate expected value differently when infinite utilities are involved. 
most controversial part of the argument. When I say I will defend this premise, I will take myself to show that the premise relies on a particular judgment about the probability of outcomes that most people will accept: namely, that the probability of an afterlife in which theists receive infinite rewards and atheists do not is more probable than an afterlife in which atheists receive infinite rewards and theists do not. Alternatively, this could be added as an assumption of my argument. Either way, being a theist will be prudentially rational for any person who accepts the crucial probability judgment. Since most people will accept the crucial probability judgment, most people will have a strong prudential reason to cultivate theistic beliefs, and so more people will fulfil condition (1) than it might seem prima facie.

\section{DEFENDING PREMISE 2}

My defence of (P2) has three elements. (i) There is a non-zero and noninfinitesimal probability that <there is afterlife in which it is possible to receive infinite utility>, (ii) the traditional way expected values are calculated should be modified to accommodate infinite utilities and (iii) the probability that <theists receive infinite utility in the afterlife and atheists do not> is higher than the probability that <atheists receive infinite utility in the afterlife and theists do not $>$. I will argue for (i) and (ii), assume (iii), and then explain how (P2) follows from (i) - (iii).

\subsection{The Possibility of Infinite Utility}

To defend premise 2, I must first establish that there is some nonzero, non-infinitesimal probability that one can receive infinite utility. Of course, if there is no chance one could receive infinite utility, then one has no reason to care which actions might be relevant for it - so all actions, including those related to one's beliefs about theism, would be irrelevant to receiving infinite utility. Since it seems implausible to suppose one might receive infinite utility during one's earthly life, I will assume if one receives infinite utility, it will happen the in afterlife (if there is one, of course). Let's called the proposition there is an afterlife in which it is possible to receive infinite utility the Infinite Utility Proposition (from here on, IUP).

Since we are worried here about pragmatic considerations (i.e. actions that would maximize expected value) and the value here we are worried about is infinite, then all that is needed for the decision matrix 
is that the probability of IUP is greater than zero and not infinitesimal. This is because, when calculating the expected value of an action $A$, the probability of a state of nature is multiplied by the utility one would gain if they performed A given that state of nature occurs. ${ }^{11}$ Since the utility in question here is infinite, as long as IUP has a non-zero, non-infinitesimal probability, actions relevant to that the outcome will have an infinite expected value. ${ }^{12}$

Before I argue that $\operatorname{Pr}($ IUP $)>0$ and non-infinitesimal, I first want to note that, if there is an afterlife, there seems to be more than one way to receive infinite utility in it. One way would be to receive finite utility for an infinite length of time, i.e. 10 utiles a day for all eternity. This might satisfy some who think that receiving infinite utility in a finite amount of time would be some sort of impossible 'supertask' for a finite person. ${ }^{13}$ However, others might have the intuition that it is metaphysically possible for a finite person to experience infinite utility in a finite amount of time, maybe at the beatific vision or as part of Divinization. One might even think infinite utility is possible in an atemporal state. For example, Eleonore Stump argues that God's existing atemporally is consistent with His mind's having a variety of faculties, experiences, and activities, such as knowing things and even experiencing emotions. ${ }^{14}$ One might think the afterlife is like that for human beings - humans have an infinitely valuable experience of being united with God, even without the passage of time. Any of these versions of the afterlife is also consistent with premise two. It is important to reiterate, however, that even if humans can receive infinite utility in a finite amount of time (or atemporally), I am assuming that this cannot occur in one's earthly life. But premise two is still relatively ecumenical; it is open to multiple ways of receiving infinite utility, and does not depend on the possibility of persons performing supertasks.

11 'State of nature' is misleading. Not only is it misleading for decision making in general (a state of nature can include possible decisions by other persons) but it also is specifically misleading in this context, as it may seem odd to think of different possible afterlives as different states of nature. However, I will retain the term because it is part of standard decision theory terminology.

12 I will be using 'expected value' and 'expected utility' interchangeably in this paper.

${ }^{13}$ One worry for this view is that there will never be a time at which I have received infinite utility. In response, it seems like there is still a clear and meaningful way in which the person in this scenario receives infinite utility, even if it there is no time at which it is completed. For more on this objection, see Vander Lann, (MS).

${ }^{14}$ See Stump and Kretzmann (1981: 18-19). 
But do we have reasons to think that IUP has a non-infinitesimal probability greater than 0 ? I think we do, for several reasons. One reason to give it a non-zero probability is that, regularity [one of the axioms of probability] states that only contradictions should receive probability 0 ; some people go even further and argue that no proposition should receive probability 0 . However, even if some propositions are given probability 0 , IUP does not seem like a likely candidate.

Two, there is an argument from peer disagreement that IUP not be assigned a zero or infinitesimal probability. Many smart people, including philosophers, theologians, and people who study religion believe IUP. While this may not give us reason to assign IUP a high probability, it seems like a reason not to assign it probability 0 or an infinitesimal probability.

Three, when one considers the large number of actions available to an all-powerful Being, this should also increase the probability of IUP. Since most stories about the afterlife are theistic, considerations about what actions are possible for an all-powerful God seem relevant when assessing the probability of IUP. If God exists, the probability that it is in his power to cause a person to experience infinite utility seems greater than 0 and non-infinitesimal.

In sum, the person who rejects IUP has a difficult burden of proof. If he wants to give it probability 0 , he must argue that some non-contradictory propositions should be assigned probability 0 . Two, he must overcome all the arguments from peer disagreement that IUP should not be assigned probability 0 /infinitesimal. Three, he must argue that the probability of IUP is zero or infinitesimal, even given the vast array of actions available to an all-powerful Being. This burden of proof seems very difficult to overcome, and in the meantime, it seems fair to conclude that $\operatorname{Pr}($ IUP $)>0$ and non-infinitesimal.

So, given that IUP has a non-zero, non-infinitesimal probability, we have a decision theoretic reason to be concerned with our post mortem destiny. But what actions are relevant to our post-mortem destiny? I will argue that one such action is the cultivation of theistic beliefs.

\subsection{An Objection from Hajek}

(P2) also depends on responding to an objection from Alan Hajek that relates to problems infinite utility creates for the expected value 
equation. ${ }^{15}$ To understand the objection, recall a simple version equation for expected value, where $[S 1, S 2 \ldots]$ are possible states of nature:

The expected value of an action $\mathrm{A}=$

$\operatorname{Pr}(\mathrm{S} 1)^{\star}$ (utility of performing A $\left.\mid \mathrm{S} 1\right)+\operatorname{Pr}(\mathrm{S} 2)^{\star}$ (utility of performing A $\mid \mathrm{S} 2)+\ldots$

Note that, for each state of nature, the relevant probability is multiplied by the relevant utility. Hajek points out that, given the equation, if the utility in question is infinite, the probability is irrelevant, as long as it is non-zero. For this reason, it isn't clear why one should directly believe in God rather than perform another action, $\mathrm{A}^{*}$, that is consistent with one's eventually coming to believe in God. As long as the probability that one will come to believe in God given that one performs $A^{*}$ is non-zero, ${ }^{16}$ one's performing $\mathrm{A}^{\star}$ has an infinite expected value. ${ }^{17}$

Hajek is correct to note that this is a problem, but rather than being a problem for arguments that one should believe in God given expected value considerations, it is an argument that we should not treat all infinities equally. Consider a scenario where there are two doors you can pick from. For each door, there is a possibility you will receive infinite utility. However, if you pick door number 1, the probability you will receive infinite utility is 0.000001 . If you pick door number 2 , the probability you will receive infinite utility is 0.999999 . For both doors, if you don't receive the infinite utility, you will be annihilated. The decision matrix is as follows:

\begin{tabular}{l|c|c|c}
\hline & Heaven & Annihilation & EV \\
\hline Door 1 & $0.000001^{\star} \omega$ & 0 & $\omega$ \\
\hline Door 2 & $0.999999^{\star} \omega$ & 0 & $\omega$ \\
\hline
\end{tabular}

If we assume that infinity multiplied by anything is infinity, both doors have the same expected value. However, this is clearly counterintuitive it seems like one should obviously pick door number 2 .

Hajek's argument and this thought experiment show that, in cases involving infinite utilities, we will need to modify the way we calculate

\footnotetext{
${ }^{15}$ Hajek (2003).

${ }^{16}$ And, presumably, non-infinitesimal.

17 Hajek (2003: 30-31).
} 
the expected values so that probabilities make a difference in the final expected values. One possible way to do this is to take the probabilities of each state of nature and then treat the utilities as a limit function, making the utilities bigger and bigger until the expected values stand in a consistent ratio to each other. I have argued for a method similar to this one elsewhere. ${ }^{18}$ There are other ways to capture these differences as well. Bartha has a version that involves taking ratios between different sizes of infinities, and Chen and Rubio have suggested a method that involves using surreal numbers. ${ }^{19}$ Whichever method you prefer, the point is that we must use an expected utility function that captures the differences in probabilities, so that all options consistent with the possibility of getting infinite utility don't turn out to have the exact same expected value.

Hajek considers these options but rejects them because he believes they are inconsistent with parts of Pascal's theology. ${ }^{20}$ Specifically, he cites textual evidence that Pascal was committed to salvation (the utility of the afterlife) being the greatest thing possible. If salvation is the greatest thing possible, reasons Hajek, then the utility of the afterlife cannot be reflexive under addition. ${ }^{21}$ Here's why: if $\omega$ represents the value of salvation, then $\omega+1$ cannot be more valuable than $\omega$. So $\omega+1$ cannot be even ordinally larger than $\omega$. The same sort of reasoning would seem to apply to multiplication: if $\omega$ is the value of salvation, $2 \omega$ cannot be more valuable than $\omega$. However, if the utility of the afterlife is not reflexive under either addition or multiplication, we cannot distinguish between $0.999999 \omega$ and $0.000001 \omega$, and so we are forced to be indifferent between door 1 and door 2 . This result seems absurd, so we should reject some part of the above reasoning.

First, I think we should clarify what it means for salvation to be 'the greatest thing possible. Changing the probability I will get something doesn't seem to change the value of the thing itself; it may change other things, such as what actions would be rational for me, but it doesn't bear on the intrinsic worth of the object. So, suppose salvation is the greatest thing possible; I see no reason to conclude from this that I should be indifferent between a 0.01 chance at it and a 0.99 chance at it. Hajek's argument seems to fail to distinguish between the value of something and

\footnotetext{
${ }^{18}$ See Jackson and Rogers 'Salvaging Pascal's Wager' (MS).

${ }^{19}$ See Bartha (2007) and Chen and Rubio (MS).

${ }^{20}$ Hajek (2003: 45-47).

${ }^{21}$ Hajek (2003: 47).
} 
my chance at getting that thing. Incorporating probabilities into decisions relevant to one's salvation is consistent with a strong conception of the maximal value of salvation. Second, 'greatest thing possible' is somewhat vague, and weaker versions of Pascal's assumption are consistent with the doctrine that different people get different afterlife benefits, i.e., your salvation is ordinally or cardinally bigger than mine. ${ }^{22}$

The lesson we should take from Hajek is this: the probability of an outcome, even an outcome with an infinite utility, matters. For two outcomes that both have infinite utilities, all else equal, the one with the higher probability has a higher expected value than the one with lower probability. Second, an outcome with a low probability and an infinite utility will always have a higher expected than an outcome with a high probability and a finite utility. ${ }^{23}$ Put another way: when ranking the expected value of outcomes, the ones with infinite utility will always be ranked above the ones with finite utility, and among the ones with infinite utility, the ones that are more probable will be ranked above the less probable.

\subsection{Theism and Maximizing Expected Value}

Now, I want to argue that one should cultivate theistic beliefs in order to maximize expected value. Note what we have established so far:

(i) There is a non-zero probability that there is an afterlife in which it is possible to receive infinite expected utility.

(ii) Our modified expected value equation will (a) always rank outcomes with infinite utility higher than those with finite utility

${ }^{22}$ For example, Jonathan Edwards suggests that the happiness each person's experiences in the afterlife is relative to their capacities (The Works of Jonathan Edwards, vol 2., p. 902). For example, I may only be able to experience 8 units of happiness a day, while someone else has the ability to experience 10 units of happiness a day. So, in heaven, we will all receive our 'maximum capacity' for happiness, but people are equipped with different capacities. This is one way to maintain that for each person, salvation is the greatest thing possible (relative to their capacities) but that we each still receive different utilities.

${ }^{23}$ For example, if we use a limit function, the religions with finite utilities will 'drop out.' If we use surreal numbers, our final values will include ordinally ranked infinite numbers, and every finite number will be ordinally ranked below all the infinite ones. So, even with a new method of calculating expected value, it is relatively easy to see that outcomes involving infinite utility will be privileged. 
and [after (a) has been applied] (b) rank outcomes with higher probability over those with lower probability. ${ }^{24}$

At this point, I want to add my crucial probability judgment that I alluded to in the explanation of premise (P2):

(iii) The probability that $<$ theists receive infinite utility in the afterlife and atheists do not $>$ is higher than the probability that $<$ atheists receive infinite utility in the afterlife and theists do not $>$.

(i) - (iii) are all we need for a full defence of premise (P2). To see why, consider a hypothetical agent, $\mathrm{S}$, who is considering whether to take actions that cultivate theistic beliefs or atheistic beliefs. Consistent with (i), $\mathrm{S}$ believes there is a non-zero probability that there is an afterlife in which it is possible for her to receive infinite expected utility. Since we assumed at the beginning of the paper the afterlife is the only means by which it is possible to receive infinite expected utility, the only states of the world we will consider are those that involve the afterlife.

Let's suppose (leaving open the question of whether God exists or not) $S$ considers three possible afterlives:

A1. Theists receive infinite utility; atheists do not.

A2. Atheists receive infinite utility; theists do not.

A3. Atheists and theists receive the same (infinite) utility.

Note that if A3 is the case, it won't matter if S cultivates theistic or atheistic beliefs. As long as A1 and A2 have non-zero probabilities for S, A3 is irrelevant. Therefore, we needn't consider A3; A1 and A2 are the only afterlives relevant for S's decision. Thus, all we need is that the $\operatorname{Pr}(\mathrm{A} 1)>\operatorname{Pr}(\mathrm{A} 2)$, which is assumed by (iii), and then, in order to maximize expected value, $S$ should cultivate theistic beliefs.

The decision matrix for the above reasoning is as follows:

\begin{tabular}{c|c|c|c}
\hline & $\begin{array}{c}\text { Theists receive } \\
\text { infinite utility, } \\
\text { atheists do not }(\mathrm{p})\end{array}$ & $\begin{array}{c}\text { Atheists receive infinite } \\
\text { utility, theists do not }\left(\mathrm{p}^{\prime}\right)\end{array}$ & EV \\
\hline Theism & $\mathrm{p} \omega$ & $\mathrm{p}^{\prime}(-\omega)$ & $\mathrm{p} \omega+\mathrm{p}^{\prime}(-\omega)$ \\
\hline Atheism & $\mathrm{p}(-\omega)$ & $\mathrm{p}^{\prime}(\omega)$ & $\mathrm{p}^{\prime}(\omega)+\mathrm{p}(-\omega)$ \\
\hline
\end{tabular}

${ }^{24}$ A more complex expected utility equation could also account for different sizes of infinity (i.e. countable infinity, uncountable infinity, etc.) For the sake of simplicity, I will assume all the outcomes refer to the same size of infinity. 
That $\mathrm{p}>\mathrm{p}$ ' is established by (iii), the crucial probability judgment. Given this, $\left[p \omega+p^{\prime}(-\omega)\right]$ will be greater than $\left[p^{\prime}(\omega)+p(-\omega)\right]$, and so in order to maximize expected value, one should cultivate theistic belief.

I explain how this conclusion interacts directly with Schellenberg in section V, but first, I respond to some objections to the above argument.

\section{OBJECTIONS}

An initial objection to the above is that belief is often taken to be involuntary. ${ }^{25}$ Attempts to believe in God for practical reasons do not guarantee that one will actually end up forming beliefs in God. So, even if many people fulfil conjunct (1) of the condition for non-resistant non-belief, they do not fulfil conjunct (2). These people, then, are not resistant, and the problem of hiddenness is unchanged.

First, even though most people do not think that we have direct control over our beliefs, we still clearly have some kind of indirect control over what we believe. We can control our belief-forming habits, what we pay attention to, what we read, who we spend time with, etc. Note that earlier in the paper, I formed the decision in question about what beliefs one should cultivate, indicating that it will be a process, rather than an immediate decision. So, we should do everything we can to cultivate belief in God. Even if one does not successfully cultivate full belief in God, it seems that one who attempted to do so and committed one's life to God in other ways would be more likely in a position to receive an infinite reward than one who didn't. Additionally, note that it is difficult to predict how successful an attempted conversion will be; one might claim that coming to believe in God would be impossible or at least very difficult, but in many cases, one cannot know this for sure until one sincerely tries. Finally, religious texts support the idea that those who attempt to cultivate theistic beliefs will succeed. ${ }^{26}$

A second way one might object to my argument is as follows: belief should only be concerned with truth. God wouldn't reward someone for believing for a decision theoretic reason; that's believing in God for a bad reason. For example, W.K. Clifford famously said that it is always wrong, everywhere, to believe without evidence. ${ }^{27}$ More recently, Antony Flew

\footnotetext{
${ }^{25}$ See, i.e. Williams (1970) and Scott-Kakures (2000).

${ }^{26}$ Matt 7:7, Jer 33:3, Deut 4:29, Rom 10:13, James 4:8, Heb 11:6.

${ }^{27}$ Clifford (1877: 5).
} 
and J.L. Mackie have advanced versions of this objection. Flew argues that believing on sufficient evidence is to reject a principle 'fundamental to personal and intellectual integrity ${ }^{28}$ and Mackie argues that trying to cultivate belief for Pascalian reasons is 'to do violence to one's reason and understanding. ${ }^{29}$

In response, I would first like to note that this seems like more of an objection to (1), my first premise, which I take myself to have assumed rather than argued for. However, one still might worry that something is defective if our belief forming habits are overly encroached by the prudential.

First, I want to note that, as stated above, I am not saying we should spontaneously and intentionally believe on the basis of my argument, but rather that we should take actions that will cause (or probably cause) our beliefs to change in certain ways. Thus, the relevant decision isn't about what to believe, but about what belief-forming habits to cultivate. But should prudential considerations play into our belief forming habits? I think they obviously should. Simple reflection on one's doxastic habits shows that prudential considerations: i.e. the importance of a belief, what's at stake given that belief, etc., seem like important guides for belief formation. For example, every time one considered any proposition $\mathrm{p}$, they could simple form the belief 'p or not p.' Additionally, one could read and believe every proposition in the phonebook. Both of these strategies would be effective ways to form lots of true beliefs, but they both seem silly to us. This is because prudential norms, not merely epistemic ones, are relevant to for one's habits of belief formation. ${ }^{30}$

If one still isn't convinced, I offer the following case. The mafia kidnaps your family and is going to kill them all unless you meet their demands. Their condition is that you take a pill that will give you the following false belief: the 500th digit of pi is 2 . (It is actually 1.) It seems clear that you should take the pill; this is a case where you should cause yourself to form a belief for a non-epistemic reason.

Third, I want to note that, even if someone takes herself to be breaking an important epistemic rule if she tries to change her beliefs for a decision theoretic reason, this can actually be incorporated into the utility function by calculating a cost for breaking the rule and subtracting

\footnotetext{
${ }^{28}$ Flew (1976: 64).

${ }^{29}$ Mackie (1982: 202).

${ }^{30}$ See Grimm (2008: 726) and Feldman (2000).
} 
it from the utility of that option. This might not be necessary in many cases, but it is also important to note that it is possible to incorporate the cost of believing on a non-epistemic basis into the expected utility equation.

Finally, I want to note that even if someone's theistic beliefs are irrational, this doesn't seem to automatically rule out their having a meaningful relationship with God. A relationship can be meaningful even if one person's belief that the other exists is unjustified. For example, suppose sceptical arguments convince me to withhold belief that my mother exists. I also have an irrational belief that magic 8-balls are infallible; I ask the 8-ball if my mother exists, and it answers 'yes'. On this basis, I come to believe in the existence of my mother. I call her and tell her I love her; I visit her and we spend time enjoying each other's company. I see no reason to think this can't be a meaningful relationship, even if my belief in my mother's existence is unjustified. ${ }^{31}$

A third objection involves the consideration that there are many different religions that are mutually exclusive. This seems troubling, because given only what I have argued above, it is unclear which religion one should pick. ${ }^{32}$ This worry includes the fact that in my sample decision matrix at the end of section III, (p) and (p') do not exhaust the probability space. My response to this is twofold. First, the main reason Schellenberg thinks God wouldn't allow non-resistant non-belief is because it seems difficult, if not impossible, to have a relationship with a being you do not believe exists. However, general theistic beliefs seem to allow the believer to have at least some sort of relationship with God. It is very unlikely that any single person has every theological doctrine correct - many people have deep, meaningful relationships with God with many incorrect beliefs about Him. For many people, basic theistic beliefs would be sufficient for a relationship with God; theists will often not count as nonbelievers in the sense relevant for Schellenberg's argument.

Second, if one can argue that the objective probability of one religion is higher than the others, when combined with my argument, there will be a powerful decision theoretic reason to cultivate belief in that religion.

${ }^{31}$ Some have suggested that God would prefer atheists who don't believe for epistemic reasons to theists who believe for prudential reasons. However, religious texts suggest this is not the case - they emphasize belief in God simpliciter, not epistemic belief to the exclusion of prudential belief.

32 Versions of this objection are made by Sober and Mougin (1994), Cargile (1966), and Mackie (1982: 203). 
Of course, cultivating theistic beliefs is an important first step, as my argument shows. But it also shows that we have a decision-theoretic reason to favour religions with an infinite utility and a high probability. Arguments that raise the probability of a particular religion, then, are potentially quite significant when considered alongside my argument above.

\section{A RESPONSE TO SCHELLENBERG}

So far, we've established that it is prudentially rational to cultivate theistic beliefs. How does this interact with Schellenberg's original argument? Consider the first conjunct of the condition for resistant non-belief:

(1) (i) $S$ believes $<$ she has a stronger reason to believe $p$ than to hold any other doxastic attitude toward $\mathrm{p}>\mathrm{OR}$ (ii) $\mathrm{S}$ is blameworthy for lacking the belief of (i).

Suppose my argument that one should attempt to be a theist is correct. It still seems like I haven't established that a large majority of people actually fulfil condition (1). It could be that, in fact, it is prudentially rational to cultivate theistic beliefs, but a very small number of people actually believe this (and so many do not fulfil (i)). Additionally, among those who are don't believe this, it is implausible that they are culpable for lacking this belief (and so many others do not fulfil (ii)). Why think that there are very few non-resistant non-believers?

Consider the first disjunct of (1). Then consider the set of all the people that have considered arguments for theism (or arguments for Pascal's Wager) and find them compelling or convincing. Many of these people will fulfil condition (i). Arguments that God exists or arguments that compel one to cultivate theistic beliefs may reduce the number of non-resistant non-believers. ${ }^{33}$

However, this is only a small number of people. What about the second disjunct of (1), condition (ii)? When is one blameworthy for lacking a belief? Even if it is true that many people should cultivate theistic beliefs, that doesn't mean they are blameworthy for failing to do so. They may not be aware of their obligation, or there may be other factors that excuse them. Still, I think there are other features of the above Pascalian argument that can closely tie it to blame, namely, the stakes involved in theism. Consider the following principle:

\footnotetext{
${ }^{33}$ See Rota (2016).
} 
Blame-Stakes Principle (BSP): For all the propositions S should believe, all else equal, the higher the stakes are with respect to a proposition $\mathrm{p}$, the more likely it is that $S$ is blameworthy for not believing the proposition $\mathrm{p}$ (or for not doing everything she can to ensure she believes that $\mathrm{p}$ ).

To see the plausibility of BSP, I will give two examples. Suppose my friend Sarah tells me she is hungry. I tell her that I have a sandwich she can have. I know the sandwich is made with either peanut butter or almond butter, but I don't know which. But it doesn't really matter; she likes both. I give her the sandwich and she eats it. This is a typical low-stakes scenario where I am not blameworthy for lacking the belief about what exactly the sandwich contains. In a second scenario, suppose the sandwich is made with peanut butter. I know Sarah absolutely hates peanut butter - it is one of her least favourite foods, and the mere thought of it makes her gag. It seems like I should check, form the belief $<$ the sandwich is made with peanut butter $>$, and not give Sarah the sandwich. In this second situation, if I give her the sandwich without checking its contents, it is more plausible that I am blameworthy. Third, suppose I know that Sarah is deathly allergic to peanut butter - so allergic, that if she eats the sandwich, she will need to be rushed to the emergency room and probably die. In this case, it is completely clear that if I don't check to see what is in the sandwich and form the corresponding belief, I am culpable. Because of the exceedingly high stakes involved in the proposition $<$ the sandwich is made with peanut butter $>$, I am responsible if I fail to form a belief about the sandwich's contents. This example shows that my failure to fulfil my duties with respect to propositions I should believe is more likely to make me culpable as the stakes get higher.

What if I am unaware of the high stakes surrounding a proposition? In some cases, this may make a difference - if, in the second scenario, I didn't know Sarah hated peanut butter, then it is plausible that I'm not culpable for giving her the sandwich without checking its contents. However, in other cases, the stakes are so high that I'm culpable for my ignorance, even if I don't have an explicit belief about the stakes. For example, in the third scenario, even vague, inconclusive evidence that Sarah is deathly allergic to peanut butter should cause me to check. I needn't have a categorical belief about the stakes; my suspicion of the mere possibility of the high stakes is enough for my culpability. Thus, I needn't have an explicit belief about the high stakes of a proposition to be culpable for my doxastic attitude toward it. 
Another case to motivate BSP: Suppose you are hiking and you come to a shallow, wide ditch that is 6 inches deep. You want to get to the other side, and for fun, you decide to see if you can jump across. The bottom of the ditch is covered in soft grass, so there is almost no chance of getting hurt if you fall. You have self-esteem issues and are notoriously pessimistic about your abilities, especially your long jumping abilities. Epistemically, you should believe that you can make the jump, but the stakes are so low that it doesn't really matter if you form the belief or not; you are not blameworthy.

Alternatively, suppose you are hiking with your child, and you come across a wide chasm. This chasm is hundreds of feet deep. You can jump across, but the only way your child can get across is if you throw him. If you don't throw him, you can't get back to base camp and he will definitely die. You are pessimistic about your throwing abilities, but this is your only chance of survival. If you do everything you can to convince yourself you will successfully get him across the chasm, you can cultivate the courage to throw him. You should believe you can make the throw successfully, and, since inevitable death of your son is the other option, it is plausible that you are blameworthy if you don't. ${ }^{34}$ This example is analogous to the wagering example in that the stakes are high, you have a forced choice, the evidence for the proposition is inconclusive, and because of the high stakes, you are blameworthy if you don't do everything you can to cultivate the belief in question.

Above, I have argued that many people should cultivate the belief that God exists. Additionally, for those that accept the crucial probability judgment, $<$ God exists $>$ is a high stakes proposition - in fact, among those with the highest stakes, because the stakes are infinite. As mentioned above, people needn't explicitly hold beliefs about these stakes to be culpable; when the stakes are very high, an awareness of even the possibility of high stakes can be sufficient for culpability. Furthermore, empirical evidence suggests that more people may be aware of these stakes than one might think. In a CBS poll of American adults, $83 \%$ of people indicated they believed in either heaven or hell, ${ }^{35}$ and, in another surprising study, $32 \%$ of people who identify as atheists and agnostics

\footnotetext{
${ }^{34}$ This example is inspired by the mountaineer example in William James' 'The Will to Believe, Part X, section 31.

35 'CBS News Poll: Americans' Views on Death.' CBSNews. (April 2014).
} 
indicated they believed in an afterlife. ${ }^{36}$ I suspect these numbers may be even higher in many places outside the US.

Now, consider the set of people who accept the crucial probability judgment. Chances are, as the surveys above indicate, quite a large number of them at least believe an afterlife is possible, and many explicitly believe in life after death. It seems like almost everyone who believes in an afterlife and accepts the crucial probability judgment would be aware of the high stakes surrounding their beliefs about God. Of course, many of these people might not be convinced they should simply do whatever they can to cause themselves to believe in God. For example, they might have a firm conviction that their beliefs should always be based on evidence. (While I argue this is false in the objections section above, I admit it has intuitive appeal.) These people may not be culpable for failing to do everything they can to cause themselves to believe in God, but they are culpable for not taking theism more seriously. They see that what one chooses to believe about God potentially has momentous consequences, but they live their lives giving God little to no thought. Surely, a subset of this group is culpable for their failure to take theism seriously, and as a result, they are resistant non-believers. Because so much hangs on one's beliefs about God, many of the world's nonbelievers are actually resistant.

So, because so much is at stake with respect to belief in God, it is plausible that many people are culpable for ignoring questions about God's existence. Those who do so are practically irrational. Many of these people are resistant non-believers. Here is another way to look at it: there are high risks and high rewards that surround the question of God's existence. The stakes are so high that many of the people who ignore these stakes and fail to believe in God are actually resistant.

\section{CONCLUSION}

In this paper, I have argued that God is not hidden because we have a decision-theoretic reason to believe in him. I have first argued that belief in God is prudentially rational as long as (i) one assigns IUP a nonzero, non-infinitesimal probability, (ii) we modify the way expected

36 'Survey: 32\% of Atheists \& Agnostics Believe in an Afterlife.' The Skeptics Guide to the Universe. (2014). 
value has been traditionally calculated to accommodate infinite utilities and (iii) the probability that $<$ theists receive infinite utility in the afterlife and atheists do not $>$ is higher than the probability that $<$ atheists receive infinite utility in the afterlife and theists do not $>$. Then, I have shown why the widespread duty to cultivate theistic beliefs, along with theism's high stakes imply it is likely that many non-believers are resistant.

While this result functions as a partial response to Schellenberg, there is room for further research. As noted at the beginning of the paper, for a full response to the deductive version of Schellenberg's argument, one would need to combine my argument with another argument that those who don't count as resistant by my lights are, in fact, resistant. Or, one could argue that, even if they aren't resistant, there is some greater good that justifies God's allowing non-resistant non-belief. While, hopefully, my argument makes either of these tasks easier than they otherwise would have been, completing these tasks could provide a complete response to the deductive version of the hiddenness argument. Second, as I note in the objection section, one could give arguments that raise the probability of a particular religion, and that would give one reason to cultivate beliefs in a particular religion. While I do not think this is necessary for responding to Schellenberg, it would enhance my basic response above. ${ }^{37}$

\section{BIBLIOGRAPHY}

Bartha, Paul. 2007. 'Taking Stock of Infinite Value: Pascal's Wager and Relative Utilities', Synthese, 154 (1): 5-52

Cargile, James. 1966. 'Pascal's Wager', in Philosophy, edited by Steven M. Cahn and David Shatz (Oxford: Oxford University Press), pp. $250 \mathrm{ff}$

'CBS News Poll: Americans' Views on Death.' CBSNews. (April 2014). Accessed

December 20, 2015. Available at: <http://www.cbsnews.com/news/cbsnews-poll-americans-views-on-death/>

Chen, Eddy, and Daniel Rubio. 'Surreal Decisions.' MS

${ }^{37}$ Thanks to Michael Rea, Chris Shields, Amanda MacAskill, Caleb Ontiveros, Trent Dougherty, Rebecca Chan, Andy Rogers, and audiences at Notre Dame's Center for Philosophy of Religion, the 2015 Eastern Meeting of the Society for Christian Philosophers, and the 2015 Meeting of the British Society for Philosophy of Religion for their helpful comments and discussions that improved this paper in many ways. Thanks especially to Michael Rea for helpful comments on many drafts of this paper. 
Clifford, W.K. 1877. 'The Ethics of Belief', Contemporary Review, 29

Dougherty, Trent. 2012. 'Reducing Responsibility', European Journal of Philosophy, 20 (4): 534-547

Edwards, Jonathan. 1998. The Works of Jonathan Edwards, vol 2. (Hendrickson Pub.)

Feldman, Richard.2000. 'TheEthics ofBelief', Philosophicaland Phenomenological Research, 60 (3): 667-695

Flew, Antony. 1976. The Presumption of Atheism and Other Philosophical Essays on God, Freedom, and Immortality (New York: Harper and Row)

Grimm, Stephen. 2008. 'Epistemic Goals and Epistemic Values', Philosophy and Phenomenological Research, 77 (3): 725-744

Hajek, Alan. 2003. 'Waging War on Pascal's Wager', Philosophical Review, 112 (1): 27-56

Jackson, Elizabeth and Andrew Rogers. 'Salvaging Pascal's Wager.' MS

James, William. 1897. 'The Will to Believe', in The Will to Believe and Other Essays in Popular Philosophy (New York: Longmans, Green, and Co.), pp. 1-15

Mackie, J. L. 1982. The Miracle of Theism: Arguments for and against the Existence of God (Oxford: Oxford University Press)

Martin, Robert. 2013. 'The St. Petersburg Paradox', in the Stanford Encyclopaedia of Philosophy. https://plato.stanford.edu/entries/paradox-stpetersburg/

Mougin, Gregory and Elliott Sober. 1994. 'Betting Against Pascal's Wager', Noûs, 28 (3): 382-395

Nover, Harris and Alan Hájek. 2004. 'Vexing Expectations', Mind 113 (450): 237 249

Rota, Michael. 2016. Taking Pascal's Wager (Downers Grove: IVP Academic)

Schellenberg, J. L. 1993. Divine Hiddenness and Human Reason (Ithaca, NY: Cornell University Press)

Schellenberg, J. L. 2005a. 'The hiddenness argument revisited (I)', Religious Studies, 41: 287-303

Schellenberg, J. L. 2005b. 'The hiddenness argument revisited (II)', Religious Studies, 41: 287-303

Scott-Kakures, Dion. 2000. 'Motivated Believing: Wishful and Unwelcome', Nous, 34: 348-75

Stump, Eleonore and Norman Kretzmann. 1981. 'Eternity', Journal of Philosophy, 78 (8): 429-458

'Survey: $32 \%$ of Atheists \& Agnostics Believe in an Afterlife.' The Skeptics Guide to the Universe. (2014). Accessed December 20, 2015. Available at: <http:// www.theskepticsguide.org/one-third-of-atheists-agnostics-believe-in-anafterlife>

Vander Lann, David. 'The Paradox of End without End.' MS 
Wainwright, William. 2001. 'Jonathan Edwards and the Hiddenness of God', in Divine Hiddenness: New Essays, edited by Daniel Howard-Snyder and Paul Moser (West Nyack, NY, USA: Cambridge University Press), pp. 98-119 Williams, Bernard. 1970. 'Deciding to Believe', in Language, Belief, and Metaphysics, edited by Howard E. Kiefer and Milton K. Munitz (Albany: SUNY Press), pp. 95-111 